\title{
Impact of Malaria on Productivity and Coping Strategies among Small -Scale Gari Processors in Odeda Local Government Area Of Ogun State Nigeria
}

Oluwalana E.O.A. and Ogunsusi 0.0

\begin{abstract}
This study examined health (malaria) as a determinant of productivity and the coping strategies employed during malaria incidence among gari processors in Odeda Local Government Area of Ogun State, Nigeria and suggest control strategy to ameliorate its effect. A total of 100 respondents were interviewed in ten communities using the simple random technique and information was gathered using a structured questionnaire. Regression analysis was used to identify significant variables affecting income while a framework was introduced to describe the socio-economic characteristics, identify the major health problems and coping strategies during malaria attack of gari processors. Regression analysis indicated that processing experience ( $a$ 0.01), prevalence of malaria ( $a$ $0.10)$, cost of tubers ( $\left.a_{0.01}\right)$, cost of firewood used $\left(a_{0.10}\right)$, and ownership of a cassava farm (a 0.01 ) were the significant factors affecting the income of the gari processors with the coefficient of $0.18,-0.87,0.68,1398.04,-0.26$ respectively. An adjusted $R^{2}$ of 0.698 (69.8\%) was obtained to explain the effect of the explanatory variables. The test of significant difference was used to test the null hypothesis, the effect of malaria on hours worked and output of gari processors showed statistical significance at $1 \%$ hence the null hypothesis was rejected. The coping strategies employed by 56 percent of the processors was the use of traditional herbs as a form of malaria treatment, 57 percent employed hired labour for processing during
\end{abstract}


malaria attack while 60 percent disclosed that they do not have access to health care within their community

The study revealed that, malaria attack has a significant effect on productivity, workers output, income and work hours of gari processors. Therefore, the study recommended among others that provision of adequate health services with due accessibility, improve their health status, thereby reducing the poverty level among gari processors in line with United Nations Millennium Development Goals (MDGs) for health by 2015.

Key word: 'Gari' processors, fermented and fried, productivity, health, MDGs

\section{Introduction}

Health is required for better quality of life, social and economic development of any country. It implies a state of social, mental and physical well-being and not necessarily the absence of disease or infirmity (WHO, 2000). It is required for better quality of life and the social and economic development of any country. Basically, it is known that a sick population is a burden to a nation and amongst other things is partly because substantial proportion of resources that could have gone for investments would be diverted to combating preventive diseases and care.

Malaria, the most prevalent tropical disease is identified as a threat to move than $40 \%$ of the world's population, and out of more than 300million acute cases each year between 1.1 and 2.7million people die each year (RBM, 2002; WHO, 2000). Majority of malaria cases (90\%) are in sub-Saharan Africa, where it constitutes $10 \%$ of the total disease burden and Plasmodium falciparum remains the main cause of serve clinical malaria and "death". In Nigeria, half of the population have at least one episode of malaria annually, and the majority of outpatient visits can be attributed to malaria $(\mathrm{FMOH}, 2001)$ while deaths have been on the increase. In the light of the entire role 
played by cassava processing as a means of income generation, improving the revenue base of the country, food security; measures aimed at enhancing productivity should also incorporate that of improved health. Opeolu and Oluwalana (2004) gave the forms of ill-health amongst gari processors mainly women to be eye problems, headache, general body weaknesses, and respiratory tract disease and fever all which affect their level of productivity. Health care delivery system, poverty and inequality are important factors that have been of great concern to health institutions particularly in the developing countries. According to Gallup and Sachs (2001), tropical health problems like malaria is geographically specific, apart from poverty, efforts to eliminate malaria in the most severely affected tropical countries have been largely ineffective whereby countries with intensive malaria had income levels in 1995 only $33 \%$ of countries without malaria without malaria whether or not they were in Africa.

Using the production function approach, Asante and Asenso-Okyere (2003) revealed that the impact of malaria on the growth in real GDP is negative and decreases $(-0.41 \%)$ for every increase in the malaria morbidity rate. Cole and Neumayer (2005) also identified a key mechanism through which health effect on growth to be via total factor productivity (TFP), using a production function and the determinant of TFP considering 3 indicators health which included malaria and however concluded that the impact of poor health on TFP is negative and significant. In addressing inequality in the provision of health services in poor countries, a study accessing access to health services found that on average the rich receive twice as much financial benefit as the poor in Africa; while in Latin America the reverse was the case (Gwartkin, 2002). 


\section{The Problem}

The role of health in rural development cannot be overemphasized. However, improved health care delivery services are not usually provided in the rural areas considering the fact that rural areas provide majority of the labour that is required and actually engage in agricultural production in Nigeria. Diseases such as malaria, tuberculosis and others common to the tropical small-scale producer populace present many serious deleterious consequences ranging from loss of work hours by labour, poor quality production, low output of both the producers of food crops as well as the processors, loss of income, diversification of capital which could be used for meaningful production processes into treatment of these diseases and even death in severe cases. Failure to wipe out and prevent resurgence can translate into a loss of majority of work force needed for efficient agricultural production in the economy. The problems identified above led to the decision to embark on the study in Odeda Local Government Area of Ogun State, Nigeria.

The study examined among other things:

- Describing the socio-economic characteristics of gari processors;

- Identifying the major health problems of gari processors;

- Analysing the effect of malaria on the productivity of Gari processors; and

- Describing the coping strategies adopted during periods of malaria attack by gari processors in the study area.

\section{Study Hypothesis}

The study hypothesized that there is no significant difference between the hours worked and output of gari processors with or without malaria 
Ho: There is no significant difference between the hours worked of gari processors with or without malaria.

$\mathrm{H}_{\mathrm{A}}$ : There is significant difference between the hours worked of gari processors with or without malaria.

Ho: There is no significant difference between the output of gari processors with or without malaria.

$\mathrm{H}_{\mathrm{A}}$ : There is significant difference between the output of gari processors with or without malaria.

\section{Methodology:}

The study was carried out in Odeda Local Government Area of Ogun State, Nigeria. The area is located in the northwest of Ogun State and has a land area of $1263.45 \mathrm{~km}^{2}$ and lies within latitudes $7^{\circ} 8^{\prime}$ and $7^{\circ} 30^{\prime} \mathrm{N}$ of the equator and longitudes $3^{\circ} 18^{\prime}$ and $3^{\circ} 17^{\prime} \mathrm{E}$. It has a population of about 99,115 people (Census, 1991) who largely speak Egba dialect, a subset of the Yoruba language in the southwest Nigeria. The Local Government shares boundaries with Ibarapa and Ido Local Government Areas of Oyo State in the North and East, while in the South and West with Abeokuta South and Obafemi/Owode Local Government Areas in Ogun State respectively. It enjoys a tropical climate with double maxima of

rainfall between April and July (short dry season in August) and from September to October while the long dry season starts in November. The Local Government Area has an average daily temperature of about $32^{\circ} \mathrm{C}$ and humidity as high as $95 \%$. The vegetation is mainly derived forest and the land is suitable for agricultural purposes.

The study utilized primary data gathered from the gari processors with the aid of a well structured questionnaire. Ten communities were randomly selected from the LGA using the least of communities in the LGA as a sampling frame. Ten gari processors were then purposively selected from each community and interviewed, given a total of 100 respondents in 
all.

Descriptive statistics such as frequency distribution and percentage tables were used to analyse the socio-economic characteristic of gari processors, their major health problem and the coping strategies adopted during periods of malaria attack.

Ordinary Least Squares (OLS) regression analysis with a generalized production function was used to determine the effect of malaria on productivity. Multiple regression analysis was used with the dependent variable being the income and the independent variables being characteristics of the processor of gari such as the household income, experience in processing, household size, the prevalence of malaria, cost of tuber processed, cost of firewood used, ownership of a cassava farm, and age of processor.

The regression model is implicitly stated as:

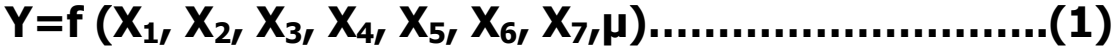

Where:

$Y=$ Household income /3months (N)

$\mathrm{X}_{1}=$ Years of Experience in gari processing (years)

$X_{2}=$ Household size (Number)

$X_{3}=$ Prevalence of malaria in household/3months

$\mathrm{X}_{4}=$ Cost of cassava tuber/ $\mathrm{kg}(\mathrm{N})$

$\mathrm{X}_{5}=$ cost of firewood $(\mathrm{N})$

$\mathrm{X}_{6}=$ Ownership of cassava farm (Dummy)

Yes (1), No (0)

$\mathrm{X}_{7}=$ Age of gari processors (years)

$\mu=$ Error term.

*Prevalence of malaria in household represents the total occurrence of malaria within the household for those actively involved in gari processing.

Three functional forms were used to estimate the regression analysis and these are the linear, semi-log and Cobb-Douglas. 
The apriori expectations of signs and magnitude of estimated parameters are such that $b_{1}, b_{6}, b_{7}>0$ (positive); $b_{2}, b_{3}, b_{4}, b_{5}$ $<0$ (negative).

The t-Test or test of significant difference was used to test the null hypothesis against the alternative hypothesis.

\section{Result and Discussion}

\section{Socio-Demographic Characteristics of Gari Processors}

The socio-demographic characteristics of the gari processors such as age, level of education, and year of experience serve as the framework for which the result of the analysis is established. As presented in Table 1, the average age of gari processors was 43years that is they are in their active age. Majority (about 85 percent) were married with an average household size of six person showing that it is easily integrated into family line, it is also gender sensitive because more females than males were involved with 93 percent being female and the average years of experience was 12 years.

\section{Major Health Problems of Gari Processors}

The major health problems of gari processors (as shown in Table 2) were malaria fever, body pain and headache. However, majority (about 77 percent) of the respondents claimed to have malaria fever as a prevalent health problem.

\section{Coping Strategies Adopted by Gari Processors During Malaria Attack}

The coping strategies employed by gari processors in the study area gives an indication of the treatment-seeking patterns and also shows how accessible the processors are to medical health centres and labour employment to compensate for the loss of work hours. As shown in Table 3, majority (about 56 percents) of the respondents use traditional herbs as their 
form of treatments by cutting part of plants and then soaking or boiling for drinking. Fifty seven percent of the respondents employed hired labour for processing during malaria attack while about 60 percent disclosed that they do not have access to health care within their community.

Table 1: Socio-demographic Characteristics of Gari Processors in the Study Area

\begin{tabular}{ll} 
Characteristic & Mode or Mean \\
\hline Age & $43 y e a r s$ \\
Marital status & $85 \%$ married \\
Gender & $93 \%$ female \\
Household size & 6 persons \\
Years of experience & 12 years \\
Educational qualification & 3 years primary \\
Main occupation & $93 \%$ gari processing \\
Ownership of cassava farm & $72 \%$ ownership
\end{tabular}

Source: Field survey, 2006.

Table 2: Major Health Problems of Gari Processors

\begin{tabular}{llll} 
Health problems & Frequency & Percentage & Cumulative \\
\hline Percentage & & & \\
Malaria fever & 77 & 77.0 & 77.0 \\
Body pain & 8 & 8.0 & 85.0 \\
Head ache & 15 & 15.0 & 100.0 \\
Total & 100 & 100.0 & \\
\hline
\end{tabular}

Source: Field survey, 2006.

Table 3: Coping Strategies Adopted During Malaria Attack by Gari Processors

Coping Strategy Mode or Mean

Health Treatment $\quad 56 \%$ Traditional herbs Labour Employment $\quad 57 \%$ Hired labour Access to Health Care $\quad 60 \%$ Non-accessibility Source: Field survey, 2006. 
Table 4: Test of Significance on effect of Malaria on hours worked and output of gari processors

\begin{tabular}{|l|l|l|l|l|l|}
\hline $\begin{array}{l}\text { Test } \\
\text { parameter }\end{array}$ & $\begin{array}{l}\text { Without } \\
\text { Malaria }\end{array}$ & $\begin{array}{l}\text { With } \\
\text { malaria }\end{array}$ & t-value & $\begin{array}{l}\text { Signi } \\
\text { fican } \\
\text { ce }\end{array}$ & Decision \\
\hline $\begin{array}{l}\text { Hours } \\
\text { worked/week }\end{array}$ & 84.73 & 30.98 & -4.93 & $* * *$ & Reject Ho \\
\hline $\begin{array}{l}\text { Output of } \\
\text { gari(kg)/week }\end{array}$ & 47.94 & 13.00 & 11.11 & $* * *$ & Reject Ho \\
\hline
\end{tabular}

Source: Data Analysis (2006)

$* * *=$ Parameter significant at $1 \%$

\section{Effect of Malaria on Productivity}

The income of the gari processors per month was influenced by certain variables, which were estimated using the CobbDouglas function as shown in equation 2.

The results from the Cobb-Douglass function was used to select the Cobb-Douglas equation as the lead equation as presented below:

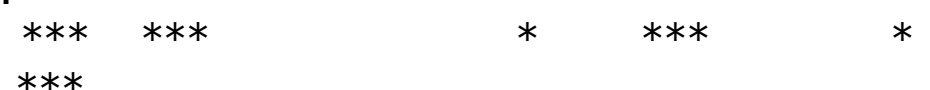

$\mathrm{Y}=16.40+0.18 \mathrm{X}_{1}+0.16 \mathrm{X}_{2}-0.87 \mathrm{X}_{3}+0.68 \mathrm{X}_{4}+$ $1398.04 X_{5}-0.26 X_{6}+0.95 X_{7} \ldots \ldots \ldots . . .(2)$

(3.64 (4.64) (0.58) (-2.85 (3.09) (2.08) (-3.49) (0.08)

$$
\mathrm{R}^{2}=0.703 \quad \mathrm{D}-\mathrm{W}=2.073
$$

Adjusted $\mathrm{R}^{2}=0.698 \quad \mathrm{~F}$ statistic $=2.796$

Note: figure in parenthesis are the t-values

$$
* * *=\left(\mathrm{a}_{0.01}\right) ; * *=\left(\mathrm{a}_{0.05}\right) ; *=\left(\mathrm{a}_{0.10}\right) .
$$

The estimated regression results for the Cobb-Douglas function provided the lead equation, based on the significance and signs of the coefficients, as well as the magnitude of the adjusted $\mathrm{R}^{2}$ and Durbin-Watson statistic. From the equation shown above, a positive sign of the coefficients implies that higher values of such variables will increase the income of gari 
processors while a negative sign indicates that higher values of the variable will decrease the income of the gari processors. As evident from the equation, a positive relationship of experience in processing, total household size, cost of tubers processed, cost of firewood used and age of the processors implies that an increase in these variables will increase the income of the processor. On the other hand, the positive relationship of the household size, cost of cassava tubers processed and the cost of firewood used contradict the apriori expectation of the sign of the estimated parameter. The reason could probably be due to the fact that increase in cost incurred on cassava tubers and firewood mean an increase in the quantity of these items available for use by the processor, hence an increase in income. For household size, an increase in size could mean an increase in labour supply for processing activity.

The negative relationship of the prevalence of malaria and ownership of a cassava form implies that an increase in these variables will reduce the income of the processors conforms to apriori expectation.

The year of processing experience, cost of tubers processed, ownership of a cassava farm show statistical significance at $a_{0.01}$; while the prevalence of malaria and the cost of firewood used show statistical significance at $a_{0.10}$ indicating that these variables increase the income of the gari processor. It was found out that household size is not significant in all the models estimated.

In equation 2 , the overall adjusted $R^{2}$ of 0.698 indicates that 69.8 percent of the variation in the income of gari processors was explained by the explanatory variables while the remaining unexplained variation (30.2 percent) may be due to other factors such as the environment and government policies. 


\section{Test of Significance on effect of Malaria on hours worked and output of gari processors}

Table 4 shows the test of significant difference on effect of malaria attack on hours worked and output of respondent gari processors. From the table, a t-value of 4.93 and 11.11 was obtained for hours worked and output respectively. The null hypothesis was then rejected in favour of the alternative hypothesis and it was concluded that malaria attack has a significant effect on hours worked and output of gari processors.

\section{Conclusion}

The analysis of the effect of malaria on the productivity of gari processors in the study area found malaria to be a significant factor affecting the productivity of small-scale gari processors. This shows that the role played by the health sector has not been fully realized in majority of the rural communities and the problem of inequality (to the detriment of the poor) has been a major barrier to the processors who later resolve into self-treatments. More attention therefore should be devoted to making the masses have adequate access to health facilities in the programme of agriculture revolution and in cases where inequality in health services occur, it should be to the favour of the poor masses. Having achieved this, food shortage problems can be overcome through increased productivity among the processors and an improved standard of living in the nation as a whole. 


\section{References}

Asante, F. A. and Asenso-Okyere, K. (2003). "Economic Burden of Malaria in Ghana". A technical Report Submitted to the World Health Organization (WHO), African Regional Office (AFRD). pp 25-28.

Cole, M. A., Neumayer, E. (2005). "The impact of poor health on Total Factor Productivity." Department of Economics, University of Birmingham, Edgbaston, Birmingham.

FMOH (2001). Federal Ministry of Health Statistical Data Federal Ministry of Health, Abuja, Nigeria..

Gallup, J. L., Sachs, J, D. (2001). "The Economic Burden of Malaria". Centre for International Development, Havard University.

Gwartkin, D. R.(2002) " Trends and Methods of Reducing Health Inequality". World Bank,Washington DC U.S.A.

Opeolu,B. O., Oluwalana, E. O. A. (2005): Environmental Health and Economic Assessment of Small and Medium Scale Cassava Processing Industry in Ogun State, Nigeria.

Roll Back Malaria (RBM) / WHO (2000). RBM Advocacy Guide, Geneva, World Health Organization

WHO (2000): Global forum on Health Research 2000-2002 World Health Organization, Geneva. 